no attempt was made to secure a high degree of accuracy. It would therefore seem as if the above method ought to prove highly applicable for the determination of $e / m$ with an accuracy perhaps greater than that obtainable by any other method.

\title{
Theory and Use of the Molecular Gage. ${ }^{1}$
}

By Saul Dushman.

EURTHER details are given regarding the construction of the vacuum gage previously described by Dr. I. Langmuir. ${ }^{2}$ The theory of the instrument is developed for both the case of low pressures and that of higher pressures. At low pressures where the mean free path is larger than the distance between the mica disc and rotating aluminum plate, the theory shows that the angle of torque of the mica disc is proportional to the rate of rotation of the aluminum plate and to the function $p \sqrt{M / R T}$, where $p$ is the pressure, $M$ the molecular weight of the gas, $R$ the gas constant and $T$ the absolute temperature.

The method of calibration and correction factors to be introduced are discussed in detail.

The instrument has been used to measure the vapor tension of mercury at room temperature, and that of ice at $-78^{\circ}$, and results obtained in agreement with those previously obtained by other investigators.

The pressures obtainable with a Gaede molecular pump were also measured by means of this instrument. A liquid air trap was inserted between gage and pump and the regular ground joint connection was used.

The speed of the pump was maintained at 8, 100 r.p.m. With a pressure of $1 \mathrm{O}^{-2} \mathrm{~mm}$. on the rough side, the best vacuum obtainable without using liquid air or heating the gage was 0.15 micron. But by heating the gage to $300^{\circ} \mathrm{C}$. for one hour and putting a liquid air flask over the trap, it was found possible to obtain a vacuum which was certainly lower than 0.005 micron (the gage was not sensitive to any smaller pressure). Under these conditions it was possible to increase the pressure on the rough side to $0.1 \mathrm{~mm}$., without increasing the pressure on the high vacuum side, and on increasing the rough side pressure to $19 \mathrm{~mm}$., the pressure in pump had increased to only 0.3 micron, giving a value of 57,000 for the ratio of pressures.

The Temperature Distribution in an Incandescent Lamp Filament NeAR a Cooling Junction. ${ }^{1}$

BY A. G. WORTHING.

$\mathrm{T}$

HE differential equation representing the distribution of temperature in a uniform cylindrical filament heated by a steady electric current, on the assumption of a constant current density, is

1 Abstract of a paper presented at the Chicago meeting of the Physical Society, November 29. I9I3.

2 Phys. Rev., April, r9r3. 